\title{
First two bilateral hand transplantations in India (Part 1): From vision to reality
}

\author{
Subramania lyer, Mohit Sharma, P. Kishore, Jimmy Mathew, Sundeep Vijayaraghavan, \\ Janarthanan Ramu, Abhijeet Wakure, Raghuveer Reddy, S. M. Mali Chetan, Visakh Varma, \\ Ashish Chaudhari, Swapnil Dhake, Akshay Omkumar, V. G. Prasad1 \\ Departments of Plastic and Reconstructive Surgery and ${ }^{1}$ Transplant co-ordinator, Amrita Institute of Medical Sciences, Kochi, \\ Kerala, India
}

Address for correspondence: Prof. Subramania lyer, Department of Plastic and Reconstructive Surgery, Tower 1, $4^{\text {th }}$ Floor, Amrita Institute of Medical Sciences, AIMS Ponekkara P. O., Kochi - 682 041, Kerala, India. E-mail: subu.amrita@gmail.com

\section{ABSTRACT}

Introduction: Vascularized composite tissue allotransplantation is a relatively new concept, which was unavailable in the Indian subcontinent till a bilateral hand transplant was carried out successfully in January 2015. Materials and Methods: The setting up of the transplant programme involved obtaining legal clearances, creating public awareness, harnessing the institutional facilities, drawing up protocols, assembling the surgical team, managing immunological issues, rehabilitation and preparing the ancillary services. Results: Both, the first and second bilateral hand transplants were resounding successes with both the recipients getting back to their original daily routines. Conclusions: The organisation of the hand transplant programme was a large task, which necessitated intensive planning, and cooperation from various teams within and outside the institution. Exemplary team-work was the key to the phenomenal success of these path breaking endeavors in the subcontinent.

\section{KEY WORDS}

Composite tissue allotransplantation; first coloured hand transplantation; India's first hand transplantation; vascularised tissue allotransplantation

\section{BACKGROUND}

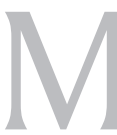
ore than 110 hand transplants have been done worldwide with the longest surviving hand transplant being 18 years now. Hand transplants are superior to prosthetic hands, especially in the case of bilateral hand amputees. ${ }^{[1]}$ Prosthetic arms

\begin{tabular}{|l|l|}
\hline \multicolumn{2}{|c|}{ Access this article online } \\
\hline Quick Response Code: & Website: \\
\hline & www.ijps.org \\
\cline { 2 - 2 } & Dol: \\
\hline
\end{tabular}

can provide some degree of assistance to carry out basic activities, but none of these can substitute a human hand. The main drawbacks of prosthetic hands are the lack of sensory feedback and its weight, especially when used for amputation at the proximal forearm level. For the Indian patients, one of the major problems faced was of

This is an open access article distributed under the terms of the Creative Commons Attribution-NonCommercial-ShareAlike 3.0 License, which allows others to remix, tweak, and build upon the work non-commercially, as long as the author is credited and the new creations are licensed under the identical terms.

For reprints contact: reprints@medknow.com

How to cite this article: Iyer $S$, Sharma $M$, Kishore $P$, Mathew J, Vijayaraghavan S, Ramu J, et al. First two bilateral hand transplantations in India (Part 1): From vision to reality. Indian J Plast Surg 2017;50:148-52. 
not being able to take care of their basic hygiene where the use of water is important.

Hand transplantation subjects the patient to long-term adverse effects of life-long immunosuppression. Baumeister et al. reported the problems related to immunosuppression after hand transplants and found them not life-threatening but having an ultimate positive impact on the quality of life. ${ }^{[2]}$ Compared to bilateral upper limb amputees, those with unilateral loss adjust with the disability much quicker and in a better manner. The risk benefit ratio of hand transplants in the unilateral amputees is less favourable than when done in bilateral amputees..$^{[3]}$

The Amrita hand transplant programme was necessitated by the requests for rehabilitation from the patients and ancillary departments of vascular surgery and orthopaedics. The hospital being a university teaching hospital and tertiary referral centre for patients coming from India and abroad, encountering patients with loss of hands and legs either unilateral or bilateral was not rare. Encouraged by the published literature on the experiences of hand transplant centres across the world we decided to establish a hand transplant programme. Considering the socioeconomic conditions of our country, we decided to accept bilateral hand amputees into the programme in the initial phases. This was done since we believed that the risk benefit ratio of transplants in bilateral loss was highly justified for our populations. His was done in spite of the fact that logistically and technically a bilateral transplant will be more demanding than a unilateral.

\section{THE SETTING UP OF THE TRANSPLANT PROGRAMME}

\section{Harnessing the Institutional facilities}

Amrita Institute started its solid organ transplant programme in 2001 when the first renal transplant took place. ${ }^{[4]}$ This was followed by the establishment of the liver transplant unit in 2004. ${ }^{[5]}$ Until the time of initiation of the hand transplant program hundreds of such solid organ transplantations has been carried out in our institution. The institution pioneered the deceased organ transplants in the State of Kerala and was an active partner of the Kerala Network of Organ Sharing (KNOS). This network is a government sponsored regulatory body with public-private participation and oversees the deceased organ donation and transplantation in the state. ${ }^{[6]}$ Internal discussions among the participating departments in the institution helped to take further planning steps. We realised that getting statutory permission for starting the programme needed organisation of the entire team beforehand.

\section{Assembling the surgical team}

The enormity of the surgery in bilateral hand transplants needed a large surgical and anaesthetic team. At least, four simultaneously working surgical teams led by the hand and microvascular surgeons was essential along with another team to work as back up both for retrieval, donor preparation and transplant. There was a need for two orthopaedic teams to help in the osteosynthesis part of the transplant to work simultaneously in tandem. The anaesthetic team had to be large to handle the recipient patient for a prolonged surgery of more than $16-18 \mathrm{~h}$. They had to be adept in handling cases involving extensive microvascular surgery, immunosuppression and possible haemodynamic challenges due to post-revascularisation bleeding. The operation theatre supporting staff needed to be arranged to provide assistance for running four separate tables and enough circulating staff, that too to be arranged at short notice. The post-operative care necessitated managing the patient both for the post-revascularisation care and the immunosuppressed status. Hence, we got a two member nursing team comprising a nurse working in the solid organ transplant Intensive Care Unit (ICU) to team up with the microvascular surgical ICU to work in each shift until the patient was stable to be transferred out of the ICU.

\section{Managing the Immunological issues}

The institution had experienced Immunology team of Nephrologists and Molecular biologists leading our renal transplant programme. Considering the similarity of the immunosuppression protocols adopted by renal and composite tissue allotransplants in the centres elsewhere, ${ }^{[7]}$ this team was inducted into our programme to oversee the immunology related issues. This included assessing the medical suitability of the potential donors and recipients, screening for occult infections, cardiovascular risk profile and age-appropriate cancer screening. The task of counselling potential recipients of the planned immunosuppression and potential shortand long-term complications of such therapy was also to be taken care of by them. The donor recipient matching was to be carried out by the team in a similar way as for renal transplants. 


\section{Preparing the ancillary services}

The main departments other than the surgical and immunology team to be initiated into the programme were transplant social workers, pathology, and the hand rehabilitation services.

\section{Transplant coordinator and social workers}

They are the key personnel in any transplant programme to prepare the recipient, his or her family and the donor families for organ donation and transplant. They were already involved in coordinating every aspect of the transplant process in the liver and kidney transplant programme of the institution. This included screening and interviewing of potential candidates, compiling medical records of the patient, ensuring that the protocol is implemented in the work-up and arranging follow up care either with the transplant team or with the patient's local physicians. This team also coordinated the deceased donor organ donations in association with the KNOS by talking to the potential donor families, liaising with the coordinators of other institutions and looking after the donor and the families until the time the body was handed over to the family. They were ready to get involved in the hand transplant programme. The main handicap was their unfamiliarity with the new programme and the reservations they had for asking for a mutilating organ donation. After several rounds of meetings, they were fully educated and convinced to work among the potential donor families.

\section{Transplant pathology}

The transplant pathological evaluations could be based on the Banff 2007 Working Classification of Skin-Containing Composite Tissue Allograft. ${ }^{[8]}$ The dermatopathologist who was also experienced in transplant pathology of solid organs was taken as the team leader for this service. Post-transplant protocol biopsies were planned weekly for the first 1 month, fortnightly for the next 2 months and monthly for the next 6 months. In case of any suspicious rash on the transplanted hand immediate biopsies were performed and analysed on a priority basis within $24 \mathrm{~h}$.

\section{Rehabilitation and hand physiotherapy}

A dedicated physiotherapy team was assigned only for the transplant patients which consisted of the physiotherapist and occupational therapist. The team was to be led by a consultant in rehabilitation medicine. Early physiotherapy was to be initiated in the $1^{\text {st }}$ week itself. Detailed protocols for physical rehabilitation as well as for assessing post-operative outcomes were set up at the beginning of the programme.

\section{Establishing protocols}

Once the transplant programme was initiated and the teams organised regular team meetings took place to establish institutional protocols. The donor and recipient selection criteria [Table 1] were drawn up. As mentioned earlier only double hand amputees were considered to be included in the potential recipient list. Individual teams drew up their protocols for surgical technique, immunosuppression regimen, detection and management of rejection episodes, physical therapy and full rehabilitation. These were presented, discussed and ratified during the multidisciplinary team meetings. Since the procedure was not considered experimental, the ethics committee felt it is out of its purview.

\section{Obtaining legal clearance}

The transplant act of 1994 was in vogue during the time when our programme was implemented (subsequently the amended act of 2014 has come into force). In this, hand was not one of the listed organs and hence to be considered under the category of 'other organs' The state government was the appropriate authority to provide sanction for the programme to be initiated. The application was forwarded to the office of the Health Secretary of the State Government which then directed the Directorate of Medical Education to inspect our facility. Inspection was carried out by two teams which comprised of specialists in Plastic Surgery, Orthopaedics and Forensic medicine. Following this, our Institute was certified on $23^{\text {rd }}$ July, 2013 as a centre for Hand transplantation by the Director of Medical Education [Figure 1].

Table 1: Inclusion and exclusion criteria for the hand transplant recipients

\begin{tabular}{ll}
\hline Inclusion criteria & Exclusion criteria \\
\hline Bilateral distal forearm amputee & Unilateral hand amputees with \\
Age 18-60 years of age & no functional, social or financial \\
Psychologically stable & impairment \\
to successfully manage & Brachial plexus injuries \\
transplanted extremities & Congenital/syndromic hand \\
Financial stability & anomalies \\
Family and social support & Paediatric traumatic amputees \\
& Medial comorbidities including \\
& malignancy \\
& HCV infection \\
& HIV infection \\
& Non-correctable acute \\
& traumatic injuries \\
\hline
\end{tabular}

HCV: Hepatitis C virus 


\section{CREATING PUBLIC AWARENESS}

Since hand transplantation is a relatively new and less performed procedure worldwide, there was a huge knowledge gap among the lay public and even medical professionals. This needed attention as we needed the ideal recipients to be in the waiting list. More of concern was the acceptance of hand donation by the potential donor families, this being a mutilating one. This need was addressed by organising talks in television health programmes and writing articles in the online media as well as the press. We also made the medical fraternity aware about the programme through personal contacts and professional talks [Figure 2]. A fixed helpline number was set up by the hospital which was handled by one of the surgeons to answer any queries regarding hand transplants and further correspondence was managed through a dedicated E-mail id.

\section{SETTING UP OF THE INITIAL LIST OF RECIPIENTS}

In response to our awareness programmes, many patients with unilateral or bilateral upper limb amputation visited the centre. For our initial cases, we had decided to select only bilateral hand amputees considering the easily justifiable risk- benefit ratio. All patients underwent an initial medical assessment and counselling session. Patients who were willing for the procedure after fully accepting the medical and economic implications of the procedure were then subjected to detailed analyses and re-counselling sessions. The patients and their families underwent counselling individually and as a group with all the teams, i.e., immunology, rehabilitation, social worker and clinical psychology [Figure 3]. After all the teams were convinced that the patient and the family have understood the medical, psychosocial and economic implications of hand transplantation and lifelong immunosuppression, two patients were selected as potential recipients. Both were in the middle ages and had lost their hands in traumatic incidents at the level of distal forearm. These patients had an amputation-listing interval of more than 1 year and had tried prosthetic rehabilitation without acceptance. They were listed on the KNOS registry enabling them to be eligible for consideration of receiving organs from brain dead donors anywhere in the state. For logistic reasons, we had insisted them to stay in proximity to the hospital, so as to arrive immediately once a suitable donor was identified.

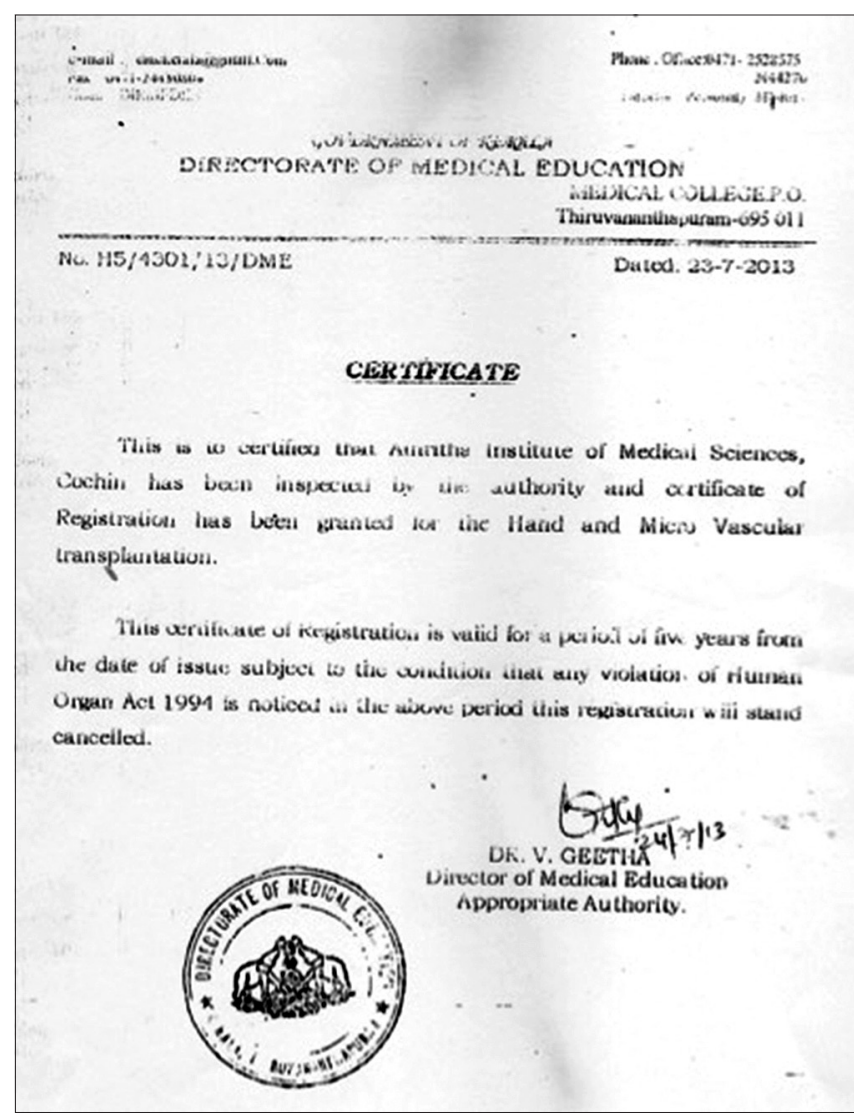

Figure 1: Approval letter for performing Hand transplantation in our institute by the Director of Medical Education, Government of Kerala

The first patient was a bilateral distal forearm amputee who had lost his hands in a train accident when he was pushed out of a running train by antisocial elements. The second patient (again a bilateral distal forearm amputee) was an Afghan army captain who had lost his hands while trying to defuse a landmine. The Afghan patient and his family had to relocate to our city while waiting for the donor. Both the recipients and families were ready for a stay of at least 1-year post-transplant in the vicinity of the hospital to facilitate the rehabilitation programme.

\section{PREPARING FOR THE DONOR AND DONOR FAMILIES}

The donor and recipient need matched for sex, blood group and ideally for size of the hands. The immunological matching was to be carried out as soon as the donor was identified. We accepted the method of complement dependent cytotoxicity assay as the method of choice, as this was the method adopted for kidney transplants in our institution. Unlike kidney or liver donation hand donation is a mutilating procedure and hence, we expected poor acceptance from the kin of the deceased donors. A pair of prosthetic hands, which closely mimicked natural hands 


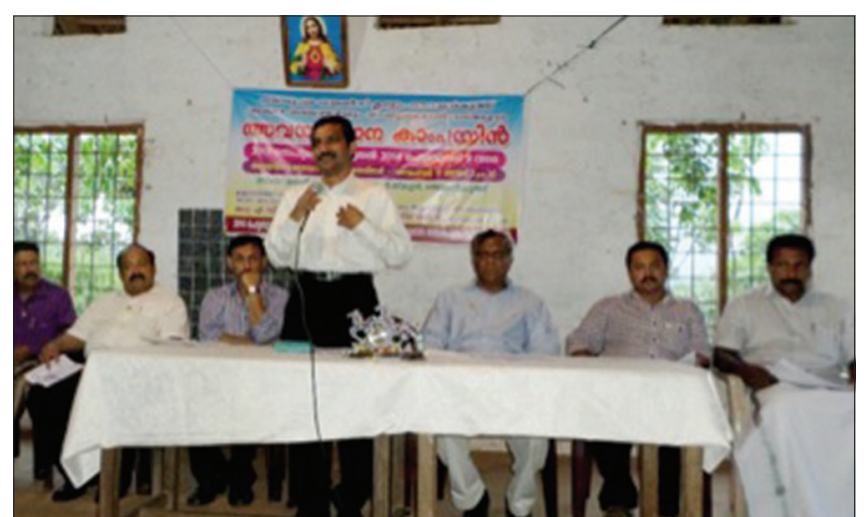

Figure 2: Public awareness meeting

and forearms, was kept available to be fitted to the body after procuring the hands. These were shown to the donor's relatives while counselling. All standard practices of donor family counselling were strictly adhered during the counselling procedure.

\section{SUMMARY}

The organisation of the hand transplant programme was a large task, which necessitated intensive planning, and cooperation from various teams within and outside the institution. All essential components of the programme could be put together from the existing technical and human resources available in the institution. This was possible only due to the strong antecedent expertise in solid organ transplants the institution had acquired. Although this was a novel procedure, getting the support and involvement form the resources outside the institution including that of the state health authorities, media and non-governmental organisations was possible by repeated interactions. When the programme is formulated the social and economic conditions of our country has to be taken into account. The suitability of the recipients to sustain the immunosuppression and rehabilitation both physically and financially has to be given importance while selecting them.

\section{Financial support and sponsorship} Nil.

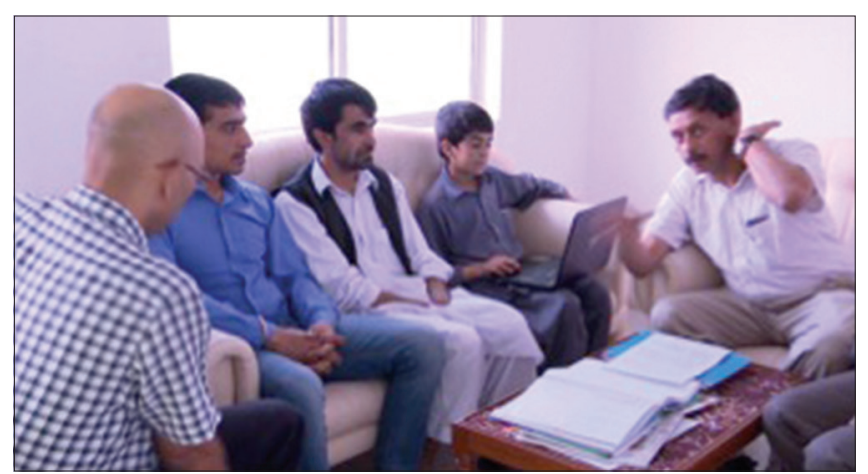

Figure 3: Family counselling sessions

\section{Conflicts of interest}

There are no conflicts of interest.

\section{REFERENCES}

1. Petruzzo $P$, Lanzetta $M$, Dubernard JM, Landin L, Cavadas $\mathrm{P}$, Margreiter $\mathrm{R}$, et al. The international registry on hand and composite tissue transplantation. Transplantation 2010;90:1590-4.

2. Baumeister S, Kleist C, Döhler B, Bickert B, Germann G, Opelz G, et al. Risks of allogeneic hand transplantation. Microsurgery 2004;24:98-103.

3. Landin L, Bonastre J, Casado-Sanchez C, Diez J, Ninkovic M, Lanzetta $\mathrm{M}$, et al. Outcomes with respect to disabilities of the upper limb after hand allograft transplantation: A systematic review. Transpl Int 2012;25:424-32.

4. Sandeep S, Srija M, Shilpa P, Mathew A, Rajesh R, Kurian G, et al. Kidney transplantation - Experience at Amrita hospital. Amrita J Med 2013;9:24-7.

5. 325 Liver Transplants in Ten Years at Amrita Institute of Medical Sciences (AIMS), Kochi. Amrita Vishwa Vidyapeetham (Amrita University); c2017. Available from: https://www. amrita.edu/news/325-liver-transplants-ten-years-amritainstitute-medical-sciences-aims-kochi. [Last accessed on 2017 Mar 11].

6. Kerala Network for Organ Sharing Mrithasanjeevani. MOHAN Foundation; c2016. Available from: http://www.knos.org.in/ default.aspx. [Last accessed on 2017 Mar 11].

7. Amirlak B, Gonzalez R, Gorantla V, Breidenbach WC $3^{\text {rd }}$, Tobin GR. Creating a hand transplant program. Clin Plast Surg 2007;34:279-89, $x$.

8. Cendales LC, Kanitakis J, Schneeberger S, Burns C, Ruiz $\mathrm{P}$, Landin L, et al. The Banff 2007 working classification of skin-containing composite tissue allograft pathology. Am J Transplant 2008;8:1396-400. 